\title{
THE PERCEPTIONS OF SIBLINGS
}

\section{The Child with Autism Spectrum \\ Disorder: The Perceptions \\ of Siblings}

\section{TERESA MACEDO COSTA and ANA PAULA DA SILVA PEREIRA}

This study sets out to understand and analyse the perceptions of six children regarding the Autism Spectrum Disorder of their brother or sister. The present research encompasses a qualitative interview method, from which semi-structured interviews were carried out to participants ranging in ages from 10 to 12 . The results of this study demonstrate that siblings, who have a high degree of knowledge and understanding about Autism Spectrum Disorder, feel less embarrassed and are better able to accept the challenges that this disorder causes. All participants indicate that: they have a solid and close relationship with their siblings, are more tolerant in the face of existing difficulties in their relationship; react negatively to the attitudes of others who are less understanding and tolerant; and are proud of their siblings with Autism Spectrum Disorder, for their progress and accomplishments. However, they continue to be unconditionally protective of their siblings in all situations.

Key words: autism, early intervention, siblings, family. 


\section{Introduction}

In accordance with existing literature, Autism Spectrum Disorder (ASD) is a disorder which poses great challenges to parents and other family members. ASD is universally characterized by deficits or impairments of social and communicative ability and repetitive stereotypic behaviours or narrow, restricted interests (American Psychiatric Association [APA], 2013)

In fact, literature suggests that when there is a child with Special Educational Needs (SEN) in the family, values and priorities are reassessed in order to reconstruct a different view, resulting in significant daily experiences (King et al., 2006; Retzlaff, 2007).

Belief systems are considered important factors that affect the adaptation and resilience of families (Walsh, 2003). These belief systems encompass worldviews, values and priorities that influence family choices about the organization and operationalization of their daily routines (King et al., 2006).

The family is formed by a group of people who remain united because of the emotional and genetic ties they share (Araujo, et al., 2012). It is usually considered the central nucleus of individualization and socialization, as well as the educational space for excellence, in which there is a permanent circularity of emotions and affections, both positive and negative, among all its members. Each element of the family is part of several systems and subsystems, interpreting, simultaneously, several roles in multiple contexts (Costa, 2004).

According to Houtzager et al., (2005), parents play an important role in sibling relationships not only in childhood and adolescence, but also in adulthood. In fact, the bond between siblings is the longest and most lasting of all human relationships since it exists from the birth of the younger sibling to the death of one of them.

Some researchers have attempted to describe, define and even explain how adolescent siblings perceive the different conditions that characterize their younger siblings with SEN (Benson \& Karlof, 2008, Kaminsky and Dewey 2002, Rivers \& Stoneman, 2008; Verté, Roeyers, \& Buysse, 2003).

Kaminsky, and Dewey (2001), report that siblings of children with ASD report low levels of intimacy, affection and pro-social behaviour on the part of their 
siblings with ASD, compared with siblings of children with Down Syndrome, and those with a typical development. On the other hand, Macks, and Reeve (2007), reinforce that siblings of children with ASD present a more positive view of their behaviour, intelligence and school performance when compared to the siblings of children with a typical development. These authors also stress that having a sibling with ASD may not be a risk factor in itself, and that those children with ASD may have positive influences on the lives of siblings with a typical development.

Petalas et al. (2012), also believe that having a sibling with ASD can have a positive impact on sharing moments of fun and enjoyment, and increasing tolerance and understanding of SEN and diversity.

According to Rivers and Stoneman (2003), brothers and sisters of children with ASD, aged between 7 and 12, express perceptions of positive interactions between siblings, feelings of pride and deep appreciation towards their sibling with ASD. Bachraz and Grace (2009), report high levels of social competence and adjustment of positive behaviour in siblings of children with ASD compared with siblings of children with typical development. During childhood or adolescence, siblings of children with ASD describe positive aspects of the sibling relationship, and consider that they are partners in the activities they develop, demonstrating lower levels of competition or conflict.

Other studies, however, refer to higher levels of depression, feelings of loneliness, shame, and less significant social interactions in adolescent siblings of children with ASD (Petalas et al., 2006). Rossiter and Sharpe (2001), verified that there is a negative influence on the psychological functioning of siblings of children with ASD, and more significantly during childhood and adolescence.

Research into the psychological adjustment of siblings of children with ASD has produced inconsistent results. Some researchers have found that there are negative results on the level of the sibling's ability to adjust to ASD (Fisman, et al., 1996; Gold, 1993; Hastings, 2003; Smalley, McCracken, and Tanguay, 1995; Verté et al., 2003); other researchers, however, have reported no significant differences in the level of psychological adjustment of siblings (Hastings, 2007; Kaminsky \& Dewey, 2002; Mates, 1990; Pilowsky et al., 2004).

According to Petalas et al. (2012), adolescent siblings report concerns about the future of their brother or sister with ASD, and state that they can play an important role in their future by recognizing or assuming their responsibilities as siblings or 
caregivers. In this sense, Tozer and Atkin (2015), reinforce that most siblings without ASD in their study maintained a strong commitment during their childhood with their brother or sister with ASD. However, despite their sense of commitment, most siblings were aware of their intense dedication to the brother or sister with SNE, and the imbalance of this dedication to other social and family obligations.

Bachraz, and Grace (2009), also report that parents of children with ASD give more time, care and attention to these children. However, the typically developing siblings did not express any kind of resentment about this, acknowledging and accepting that their sibling had additional care needs.

In fact, families balance their strengths, resources and challenges to meet the needs of all their members. Therefore, it is clear that the needs of the child with ASD often occupy a central place in the structuring of daily family routines. However, it is equally evident that young children accept the importance of this restructuring and are constituted as active members in the adaptation and accommodation of family routines (Bachraz \& Grace, 2009).

Communication and information about ASD passed on by parents is considered an important factor in the promotion of understanding on the part of siblings. According to Dellve, Cernerud, and Hallberg (2000), siblings who have a greater knowledge and understanding about ASD, show less embarrassment in their relationship with their sibling with ASD, and greater acceptance of the circumstances that are inherent in this disorder.

Taking this evidence into account, this article aims to understand and analyse the perceptions of six participants in relation to the ASD of their brother or sister.

\section{The research approach}

This study followed a qualitative methodology, characterised by being descriptive and containing in the context the direct source of data, and with the researcher being the main instrument. It puts a greater focus of interest on the process than the results or products, and tends to induce data analysis and gives meaning a central importance (Bogdan \& Biklen, 2010). In this sense, two research questions were defined in this study: 1) How does ASD influence the lives of children whose siblings have been diagnosed with ASD? 2) How do children advocate the rights of their siblings with ASD? 


\section{Participants}

The choice of participants was intentional and was conducted primarily to maximise what could be learned about the matter under study (Patton, 2002; Stake, 2007). In this sense, it was a gradual process, during which an attempt was made to increase the probability of finding and including in the study multiple realities, considering the existing differences like enriching contributions for the construction of a deeper understanding about the subject under study (Bogdan \& Biklen, 2010).

The following were defined as the inclusion criterion: Children between the ages of 10 and 15 who had at least one sibling with a formal diagnosis of ASD, and who were able to share relevant and comprehensive experiences, knowledge and perspectives on the subject under study (Aires, 2015). Participants in this study are six siblings of children with ASD; aged 10 to 12 years (see Table 1).

The parents of the participants and the participants themselves were contacted personally and given a brief presentation of the study, the objectives to be achieved, the respective procedures and rules for participation and confidentiality. All of the parents concerned agreed to their children's participation in the study, and all participants agreed to cooperate. Interviews were then scheduled according to the availability and location chosen by the participants.

\section{The data-gathering instrument}

According to Bogdan and Biklen (2010), the semi-structured interview allows the researcher to conceive an idea about how participants interpret aspects of the phenomenon under study.

Table 1. Characterization of Participants

\begin{tabular}{|c|c|c|c|c|}
\hline \multicolumn{3}{|c|}{ Participant profile } & \multicolumn{2}{|c|}{ Profile of sibling with ASD } \\
\hline Gender & Age & School level & Gender & Age \\
\hline female & 11 & $6^{\text {th }}$ year & male & 7 \\
\hline female & 10 & $5^{\text {th }}$ year & female & 12 \\
\hline male & 10 & $5^{\text {th }}$ year & male & 11 \\
\hline female & 10 & $5^{\text {th }}$ year & male & 5 \\
\hline female & 12 & $7^{\text {th }}$ year & male & 10 \\
\hline male & 12 & $7^{\text {th }}$ year & male & 13 \\
\hline
\end{tabular}


Previously, a script with structured questions was elaborated which focused on the research objectives (Amado \& Ferreira, 2017). The validation of this preliminary script was done through an interview with a child who met the criteria for inclusion in the study but was not part of it. This process allowed for a careful study and revision of the content and format of the questions, and confirmed their suitability for the analysis of the research objectives. In this way, the instrument used in the data collection was the semi-structured interview.

All the interviews were carried out by the same investigator, and lasted about 45 minutes. Every interview was conducted at a place and time convenient for the family.

One of the interviews took place in a café near the home of the participant and the other five were performed in the school attended by the participants.

Data collection was carried out using a digital recorder which was later transcribed and digitalized by the investigator.

\section{Data analyses}

As a technique for addressing the data collected, content analysis was used. Content analysis involves the systematic organization of collected information, in order to deepen its understanding and facilitate the presentation of results (Amado, Costa \& Crusoé, 2017; Bardin, 2009).

Content analysis was conducted by applying the following:

a. Constitution of the corpus - That is, the identification of the universe of analysis, which in the case of this study is equivalent to data collected through semi-structured interviews (transcripts and field notes);

b. Separation in codification units - This corresponded to the decomposition as a whole, including in each interview the content segment that constituted the basis for the elaboration of the categorization;

c. Specification of a system of categories - In order to carry out this analysis, it was fundamental to detail a system of categories, which enabled the conceptual classification of units referring to the same topic (Bardin, 2009).

The category systems used in this research was developed at different times (before, during and after data collection) using inductive and deductive analysis. 
Table 2 shows the system of categories and subcategories developed and used in this study.

\section{Results and discussion}

The presentation of the results was carried out taking into account the research's empirical questions, and the category systems taken from the content analysis of the research data (Bardin, 2009).

\section{Knowledge about ASD}

All participants reported that the knowledge about the ASD of their siblings was transmitted to them by their parents. One participant says that although she was informed by her parents, they did not give her the necessary knowledge about the characteristics of her brother's ASD. Another participant explained that she was aware of her sister's difference as she grew up because "she sometimes acts differently from others." Seligman and Darling (2007), argue that parental communication with children without SEN regarding siblings with SEN is an important factor in promoting the relationship and understanding about Special Needs.

Participants also reported that they do not ask their parents about their siblings' ASD. One participant mentions "I already know what I need to know", while another says "I do not feel the need to ask my parents questions, I have become used to being with him". Orsmond and Seltzer (2007), report that although they feel they are informed, more than half of the siblings of children with ASD have not been able to explain the needs of their brother or sister.

Table 2. Category Systems

Category 1:

Category 2:

Subcategory 2.1

Subcategory 2.2

Category 3:

Subcategory 3.1
Knowledge about ASD

Influence of ASD on one's self

Feelings

Relationships

Influence of the attitudes of others regarding ASD

Sharing knowledge about ASD

Advocacy of the rights of the sibling with ASD 


\section{Influence of ASD on the individual}

\section{Feelings}

In contrast to the results of different studies indicating that there are difficulties in dealing with the aggressive behaviour of a brother or sister with ASD (Benderix \& Sivberg, 2007; Mascha \& Boucher, 2006; Petalas et al., 2009; Ross \& Cuskelly, 2006), none of the participants in this study demonstrated the need to deal with aggression on the part of siblings with ASD, although one of the participants admitted to feeling "strange" with some of the actions and behaviour of the sister with ASD. This is consistent with other studies carried out with siblings of children with ASD, who demonstrated that the siblings reported strange behaviours and feelings of embarrassment regarding the sibling with ASD (Benderix \& Sivberg 2007; Petalas et al., 2009; Roeyers \& Mycke, 1995). The six participants of this study acknowledged that they did not feel sad, upset, angry, embarrassed or anxious about the behaviour of their brother or sister with ASD. These results are in agreement with the data obtained by Macks and Reeve (2007), who found that the majority of participants in their study considered that the presence of a brother or sister with ASD did not affect the relationship and intimacy between siblings.

All participants say that the reciprocity of their relationship with their sibling is limited, which sometimes involves having to forgo certain games or activities to satisfy the sibling with ASD. However, they do not express feelings of loss or resentment because they have a different relationship from other siblings, and refer to being satisfied with their relationship. This data is therefore contradictory to that obtained by Tozer and Atkin (2015), who report that most of the siblings in their study expressed a sense of sadness and frustration with the lack of reciprocity in relationships with siblings with ASD, namely a sense of loss for not having a typical sibling relationship.

With respect to the way ASD influences the lives of siblings, five of the six participants report that parents attribute and focus their attention almost exclusively on the brother or sister with ASD. One participant stressed: "He has to work harder and sometimes my parents do not have as much time to help me do what I need too." Macks and Reeve (2007), also report that siblings of children with ASD receive less parental attention and support.

However, participants in this study did not express any kind of resentment about parents paying less attention to them, recognizing and accepting that their 
siblings have additional care needs. This result is emphasised by Bachraz and Grace (2009), who report that the parents of children with ASD provide more attention and time to the care of the child with ASD. On the other hand, young children accept this fact and are active in adapting to and accommodating family circumstances.

\section{Relationships}

The presence of SEN for one of the siblings may be an additional factor that influences the life course and the relationship between siblings (Orsmond \& Seltzer, 2007). Most participants in this study have revealed a close relationship with their sibling stating that they play together every day. One participant said: "She likes to play with me, she laughs a lot."

Moyson and Roeyers (2011) argue that positive and negative experiences are intrinsically linked to sibling relationships because siblings themselves try to minimize the impact of ASD on their lives. Ross and Cuskelly (2006) report that interactions between siblings provide opportunities for experiencing and manifesting many emotions, as well as practising them, and possibly mastering skills such as self-control, conflict resolution, sharing, and listening.

It is notable in this study that the relationship between participants and their siblings provides positive and negative experiences. Although all participants report having a solid and close relationship with their siblings, they also report some difficulties in their interaction, such as "he doesn't understand that it is my turn to do things."

All the participants encountered difficulties in understanding on the part of the sibling with ASD. "The most difficult thing is that he does not understand things and, for example, his colleagues say something and he repeats it because he does not know what it is (...) even once his schoolmates used a bad word and he came home and repeated it." One participant says that sometimes she is upset that her brother does not understand when it is time to take turns, while another participant mentions that games "sometimes go wrong", in the sense that the brother does not respect the rules of the game.

It is also important to note that having a sibling with ASD can have a positive impact, and this is recognized by all participants. In this sense, one of the participants said: "It's not difficult at all, we get along very well and she likes me very 
much". Petalas et al. (2012), report that in their study, the siblings demonstrated an increase in tolerance and understanding regarding SEN and considered it positive to share moments of fun and pleasure.

Along the same line of thought, Bachraz and Grace (2009), report high levels of social competence and positive behavioural adjustment in siblings of children with ASD, compared with siblings of children with typical development. They further reinforce that during childhood or adolescence, siblings of children with ASD describe positive aspects of the relationship, such as being partners in activities, showing great admiration for siblings and lower levels of competition or conflict. Furthermore, Trubia et al. (2016), also point out that there is equity in the sharing of feelings and affection between siblings with and without ASD.

Data from this study also demonstrate that participants share moments of play and fun with their siblings, and that they have a great sense of tolerance when their siblings behave differently during playtime. In fact, no participant mentioned the existence of competition between the siblings, and stressed the importance of minimizing conflicts. In this sense, the participants consider that they should not contradict the decisions of the sibling with ASD and by doing so, avoiding the development of a crisis in behaviour. At this level a participant points out: "if he does something different from what I am doing, I just let him play as he wants."

\section{Influence of the attitudes of others regarding ASD}

A sense of uncertainty and tension is evident in some studies with adolescent (Opperman \& Alant, 2003; Petalas et al., 2009), and adult siblings (Tozer, Atkin, $\&$ Wenham, 2013). Feelings of embarrassment, frustration, and anger occur when siblings of children with ASD feel compelled to deal with the attitudes and reactions of others, and even when they need to explain their sibling's condition to their peers (Petalas et al., 2009).

Most participants in this study, however, reported feeling good about talking to their colleagues and friends about their brother or sister's ASD, and did not show feelings of embarrassment, frustration or anger. They admit to being comfortable, although one of the participants indicates that colleagues do not "understand very well" what it means to be the brother or sister of a child with ASD. 
Opperman, and Alant (2003), reported that most of the adolescents participating in their study felt that their peers did not accept their sibling with SEN and did not often know how to act towards them. Roeyers and Mycke (1995), also demonstrated that siblings of children with ASD felt more ashamed in the presence of other children and colleagues than other sibling groups of children of other SEN categories.

All respondents report that they react poorly to inappropriate attitudes of others towards their siblings with ASD. They also admit to being upset or very angry when someone makes a disparaging comment about their brother or sister with ASD. However, only two participants reported having heard disparaging remarks about their siblings. According to Skär (2010), children respond positively to a child with perceptible SEN (for example, a child in a wheelchair or crutches), but they respond with prejudice, suspicion and a lack of understanding to less perceptible SEN children, like those with ASD).

\section{Sharing knowledge about ASD}

In relation to the sharing of knowledge about the ASD of the siblings, the participants present different perspectives. One of the participants indicated that she had talked "with some people who did not know what was going on with Matilde". Two of the six participants report that they talk about ASD with their closest friends and extended family members, and mentioned that they do not feel constrained in doing so. Finally, one participant declares, "I only speak to my mother," and does not share information about the ASD of the sibling with other family members, colleagues, or others. Orsmond and Seltzer (2007), reported that more than half of the siblings of children with ASD who participated in their study were not able to explain the needs of their brother or sister, and a third said they could only talk to someone outside the family about the condition of their sibling.

\section{Advocate the rights of siblings with ASD}

All participants said they were proud of the progress made by their siblings with ASD. One of the participants expressed pride in their brother "when he can do things he could not do before." These data are in line with those found in the study carried out by Stalker and Connors (2004), who report that participants 
in their study do not see their siblings with ASD as essentially different from themselves.

According to Bachraz and Grace (2009), the participants of their study described their sibling with ASD as an individual with unique and distinct characteristics. The beliefs of the participants are based on family beliefs and these participants see their siblings with ASD as complete individuals with personal strengths and weaknesses. The results obtained by Bachraz and Grace (2009), are equal to those obtained in this study, because the differences in the behaviour of the children with ASD were not presented as something that needed to be altered, instead they are considered an integral part of the way of being of the child with ASD.

In a qualitative study by Tozer and Atkin (2015), the results suggest that most siblings without ASD maintained a strong commitment with their brother or sister with ASD, which was well established during childhood. However, despite their sense of commitment, most of the siblings were also aware of their intense dedication to the brother or sister with SEN, and the imbalance of that dedication in relation to other social and family obligations.

Participants in this study consider that they give more than they receive in their relationship with their sibling with ASD. Often, they consider themselves as a second parent yet they do not obtain any type of compensation for the support they provide. According to Tozer et al. (2013), this result is similar to that found among siblings in the general population, yet more particularly, brothers and sisters of children with ASD as feel they have increased long-term commitment and responsibility for their siblings.

Literature in general reports that adult siblings of individuals with ASD demonstrate a strong emotional link, and assume increased family responsibilities in relation to their siblings with ASD, compared to their peers with siblings with a typical development (Petalas et al., 2009; Seltzer et al., 2005). This is of particular importance in times of transition, since many siblings leave their parents' homes to keep in touch with their sibling with SEN, and providing them with ongoing support (Heller \& Kramer 2009).

In fact, all the participants of this study revealed to being quite protective towards their siblings with ASD, affirming that this is the role they represent in the dynamics of their relationship. Two of the participants say they take great 
responsibility for their siblings, mainly because; "I am the older sister". All the participants reported that if they had the opportunity to change something about their brother or sister with ASD, they would not, because they like them as they are.

\section{Conclusion}

There are several studies that attempt to define, describe and even explain how the adolescent siblings of children with SEN perceive the different conditions that characterize their younger siblings (Benson \& Karlof, 2008; Kaminsky \& Dewey, 2002; Rivers \& Stoneman, 2003).

According to several studies, the presence of a sibling with ASD has negative effects on the other siblings (Marciano \& Scheuer, 2005; Moyson \& Roeyers, 2011; Orsmond \& Seltzer 2007; Yoder et al., 2009). What is more, some studies highlight the existence of greater emotional problems and higher levels of anxiety in those siblings of children with ASD (Fisman et al., 1996; Fisman et al., 2000, Hastings 2003, Verté et al., 2003; Constantino et al., 2006; Giallo \& GavidiaPayne, 2006; Ross \& Cuskelly, 2006).

In contrast, other studies refer to the existence of positive feelings in the relationship between siblings with and without ASD (Benson \& Karlof, 2008; Kaminsky \& Dewey, 2002; Macks \& Reeve, 2007; Walton \& Ingersoll, 2015).

However, Macks and Reeve (2007), consider that having a sibling with ASD may not be a risk factor in itself, and that children with ASD can positively influence the lives of siblings with a typical development. Moreover, interactions between siblings provide opportunities for experiencing and manifesting many emotions, as well as demonstrating them, and possibly mastering skills such as self-control, conflict resolution, sharing and listening. Therefore, siblings of children with ASD play an important role in the promotion of these interactions (Petalas et al., 2012).

Based on these assumptions, this study aimed to analyse and understand the perception of adolescents in relation to their brother or sister with ASD. The results of this study allow us to conclude that siblings who have a greater knowledge and understanding about ASD, and who have an open dialogue with parents and the family, share their knowledge with the rest of the family, with friends and even 
with strangers. Moreover, they also reveal less embarrassment in the relationship with their sibling with ASD and greater acceptance of the challenges they face daily.

Regarding the way the ASD influences their lives, the participants feel that their lives are subjected to several influences. In this sense, they emphasize the discrepancy that exists in the level of availability and attention given by their parents, compared to the availability and attention that their parents give to their siblings with ASD. They also mention the influence of the unpredictability of the behaviour of the brother or sister with ASD in the different contexts they are in. Despite these influences, the siblings of children with ASD report that they do not feel the impact of this disorder on their lives as negative. However, this data is not consonant with the study by Tozer and Atkin (2015), in which the participants reveal feelings of loss because they have a different relationship to that of other siblings.

Regarding the negative attitudes of others towards ASD, the participants are equally unanimous when they report that they react badly to the less adequate attitudes of others towards their siblings with ASD, and admit to being upset or very angry when someone makes a disparaging comment about their sibling. Although only two participants have heard derogatory remarks about their siblings, the remaining participants admit to feeling hurt by comments made about their siblings with ASD.

Another significant point is the importance of the knowledge acquired by these brothers and sisters in relation to ASD. As a result, participants who are more knowledgeable about ASD, and who talk openly with their parents and close family members share this knowledge with other family members, friends, and even with strangers.

Also of great importance is the feeling of pride that all participants admitted to nurturing by their brother or sister, since all participants said they were proud of the progress made by their siblings with ASD. This is in line with other studies that point out that children do not consider their siblings with ASD to be different from them, reinforcing the idea that they feel an increased commitment and responsibility to their siblings in the long run, contrary to the results found among siblings in the general population (Stalker \& Connors, 2004; Tozer et al., 2013). 
It is also important to note that among the data shared by the participants, it is quite notable that they describe the brother or sister with ASD as an individual with a unique way of being. In the eyes of their siblings, the differences that children with ASD present are seen as peculiar characteristics that form an integral part of their way of being. In this context, all the participants say that they would not change anything in their brother or sister with ASD, because they like them exactly as they are. According to Petalas et al. (2012), providing support and promoting positive relationships between siblings with and without ASD, provides mutual benefits for siblings and other family members.

\section{References}

AIRES, L. (2015) Paradigma qualitativo e práticas de investigação educacional [Qualitative paradigm and educational research practices]. Porto: Universidade Aberta.

AMADO, J. and FERREIRA (2017) A entrevista na investigação em educação [The interview in education research]. InJ. Amado (Ed.), Manual de Investigação Qualitativa em Educação, pp. 209-235. Coimbra: Imprensa da Universidade de Coimbra.

AMADO, J., COSTA, A.P. and CRUSOÉ, N. (2017) A Técnica de análise de conteúdo [The content analysis technique]. InJ. Amado (Ed.) Manual de Investigação Qualitativa em Educação, pp. 301-350. Coimbra: Imprensa da Universidade de Coimbra.

American Psychiatric Association (APA) (2013) Diagnostic and statistical manual of mental disorders. Fifth Edition, DSM-5. Washington DC: A.P.A.

ARAUJO, R.R., SOUZA-SILVA, J.R. and D'ANTINO, M.F. (2012) Breve discussão sobre o impacto de se ter um irmão com transtorno do espectro do autismo [Brief discussion of the impact of having a sibling with autism spectrum disorder]. Cadernos de Pós-graduação em Distúrbios do Desenvolvimento, 12, 1, 9-15.

BACHRAZ, V. and GRACE, R. (2009) Creating a different kind of normal: Parent and child perspectives on sibling relationships when one child in the family has autism spectrum disorder. Contemporary Issues in Early Childhood, 10, 4, 317-330.

BARDIN, L. (2009) Análise de conteúdo [Content analysis]. Coimbra: Edições.

BENDERIX, Y. and SIVBERG, B. (2007) Siblings' experiences of having a brother or sister with autism and mental retardation: A case study of 14 siblings from five families. Journal of Pediatric Nursing, 22, 5, 410-418.

BENSON, P.R. and KARLOF, K.L. (2008) Child, parent, and family predictors of latter adjustment in siblings of children with autism. Research in Autism Spectrum Disorders, 2, 4, 583-600.

BOGDAN, R.C. and BIKLEN, S.K. (2010) Investigação qualitativa em educação: Uma introdução à teoria e aos métodos [Qualitative research in education: An introduction to theory and methods]. Porto: Porto Editora.

CONSTANTINO, J.N., LAJONCHERE, C., LUTZ, M., GRAY, T., ABBACCHI, A., MCKENNA, K., et al. (2006) Autistic social impairment in the siblings of children with pervasive developmental disorders. The American Journal of Psychiatry, 163, 2, 294-296.

COSTA, M.I. (2004) A família com filhos com necessidades educativas especiais [The family with children with special educational needs]. Journal of Education, Techologies, and Health, 30, 9, 74-100. 
DELLVE, L., CERNERUD, L. and HALLBERG, L.R.M. (2000) Harmonizing dilemmas: Siblings of children with DAMP and Asperger syndrome's experiences of coping with their life situations. Scandinavian Journal of Caring Sciences, 14, 3, 172-178.

FISMAN, S., WOLF, L., ELLISON, D., GILLIS, B., FREEMAN, T. and SZATMARI, P. (1996) Risk and protective factors affecting the adjustment of siblings of children with chronic disabilities. Journal of the American Academy of Child \& Adolescent Psychiatry, 35, 11, 1532-1541.

FISMAN, S., WOLF, L., ELLISON, D. and FREEMAN, T. (2000) A longitudinal study of siblings of children with chronic disabilities. Canadian Journal of Psychiatry, 45, 4, 369-375.

GIALLO, R. and GAVIDIA-PAYNE, S. (2006) Child, parent and family factors as predictors of adjustment for siblings of children with a disability. Journal of Intellectual Disability Research, $50,12,937-48$.

GOLD, N. (1993) Depression and social adjustment in siblings of boys with autism. Journal of Autism and Developmental Disorders, 23, 1, 147-163

HASTINGS, R.P. (2003) Brief report: behavioral adjustment of siblings of children with autism. Journal of Autism and Developmental Disorders, 33, 1, 99-104.

HASTINGS, R.P. (2007) Longitudinal relationships between sibling behavioral adjustment and behavior problems of children with developmental disabilities. Journal of Autism and Developmental Disorders, 37, 8, 1485.

HELLER, T. and KRAMER, J. (2009) Involvement of adult siblings of persons with developmental disabilities in future planning. Intellectual and Developmental Disabilities, 47, 3, 208-219.

HOUTZAGER, B.A., GROOTENHUIS, M.A., CARON, H.N. and LAST, B.F. (2005) Sibling self-report, parental proxies, and quality of life: the importance of multiple informants for siblings of a critically ill child. Pediatric Hematology and Oncology, 22, 1, 25-40.

KAMINSKY, L. and DEWEY, D. (2001) Siblings relationships of children with autism. Journal of Autism and Developmental Disorders, 31, 4, 399-410.

KAMINSKY, L. and DEWEY, D. (2002) Psychosocial adjustment in siblings of children with autism. Journal of Child Psychology and Psychiatry, 43, 2, 225-232.

KING, G.A., ZWAIGENBAUM, L., KING, S., BAXTER, D., ROSENBAUM, P. and BATES, A. (2006) A qualitative investigation of changes in the belief systems of families of children with autism or Down syndrome. Child: Care, Health and Development, 32, 3, 353-369.

MACKS, R.J. and REEVE, R.E. (2007) The adjustment of non-disabled siblings of children with Autism. Journal of Autism and Developmental Disorders, 37, 1060-1067. https://doi.org/10.1007/ s10803-006-0249-0.

MARCIANO, A.R.F. and SCHEUER, C.I. (2005) Quality of life in siblings of autistic patients. Revista Brasileira de Psiquiatria, 27, 1, 67-69.

MASCHA, K. and BOUCHER, J. (2006) Preliminary investigation of a qualitative method of examining siblings' experiences of living with a child with ASD. The British Journal of Development Disabilities, 52, 102, 19-28.

MATES, T.E. (1990) Siblings of autistic children: Their adjustment and performance at home and in school. Journal of Autism and Developmental Disorders, 20, 4, 545-553.

MOYSON, T. and ROEYERS, H. (2011) The quality of life of siblings of children with autism spectrum disorder. Exceptional Children, 7, 1, 41-55.

OPPERMAN, S. and ALANT, E. (2003) The coping responses of the adolescent siblings of children with severe disabilities. Disability and Rehabilitation, 25, 9, 441-454.

ORSMOND, G.I. and SELTZER, M.M. (2007) Siblings of individuals with autism spectrum disorders across life course. Mental Retardation and Developmental Disabilities Research Reviews, $13,4,313-320$. 
PATTON, M.Q. (2002) Qualitative research \& evaluation methods (third edition). Thousand Oaks: Sage Publications.

PETALAS, M.A., HASTINGS, R.P., NASH, S., DOWEY, A. and REILLY, D. (2009) "I like that he always shows who he is": The perceptions and experiences of siblings with a brother with autism spectrum disorder. International Journal of Disability, Development and Education, 56, 4, 381-399.

PETALAS, M.A., HASTINGS, R.P., NASH, S., REILLY, D. and DOWEY, A. (2012) The perceptions and experiences of adolescent siblings who have a brother with autism spectrum disorder. Journal of Intellectual \& Developmental Disability, 37, 4, 303-314.

PILOWSKY, T., YIRMIYA, N., DOPPELT, O., GROSS-TSUR, V. and SHALEV, R.S. (2004) Social and emotional adjustment of siblings of children with autism. Journal of Child Psychology and Psychiatry, 45, 4, 855-865.

RETZLAFF, R. (2007) Families of children with Rett syndrome: Stories of coherence and resilience. Families, Systems, \& Health, 25, 3, 246-262.

RIVERS, J.W. and STONEMAN, Z. (2003) Sibling relationships when a child has autism: Marital stress and support coping. Journal of Autism and Developmental Disorders, 33, 4, 383-394.

RIVERS, J.W. and STONEMAN, Z. (2008) Child temperaments, differential parenting, and the sibling relationships of children with autism spectrum disorder. Journal of Autism and Developmental Disorders, 38, 9, 1740-1750.

ROEYERS, H. and MYCKE, K. (1995) Siblings off a child with autism, with mental retardation and with a normal development. Child: care, health and development, 21, 5, 305-319.

ROSS, P. and CUSKELLY, M. (2006) Adjustment, sibling problems and coping strategies of brothers and sisters of children with autistic spectrum disorder. Journal of Intellectual and Developmental Disability, 31, 2, 77-86.

ROSSITER, L. and SHARPE, D. (2001) The siblings of individuals with mental retardation: a quantitative integration of the literature. Journal of Child and Family Studies, 10, 1, 65-84.

SELIGMAN, M. and DARLING, R.B. (2007) Ordinary families, special children: a systems approach to childhood disability (third edition). New York: The Guilford Press.

SELTZER, M.M., GREENBERG, J.S., ORSMOND, G.I. and LOUNDS, J. (2005) Life course studies of siblings of individuals with developmental disabilities. Mental Retardation, 43, 5, 354-359.

SKÄR, L. (2010) Children's conceptions of the word 'disabled': A phenomenographic study. Disability \& Society, 25, 2, 177-189

SMALLEY, S.L., MCCRACKEN, J. and TANGUAY, P. (1995) Autism, affective disorders, and social phobia. American Journal of Medical Genetics Part A, 60, 1, 19-26.

STAKE, R.E. (2007) A arte da investigação com estudos de caso [The art of research with case studies]. Lisboa: Fundação Calouste Gulbenkian.

STALKER, K. and CONNORS, C. (2004) Children's perceptions of their disabled siblings: 'She's different but it's normal for us'. Children \& Society, 18, 3, 218-230.

TOZER, R. and ATKIN, K. (2015) "Recognized, valued and supported"? The experiences of adult siblings of people with autism plus learning disability. Journal of Applied Research in Intellectual Disabilities, 28, 4, 341-351.

TOZER, R., ATKIN, K. and WENHAM, A. (2013) “My brother likes meeting new people, but don't ask him any direct questions": Involving adults with autism plus learning disability in a qualitative research project. British Journal of Learning Disabilities, 42, 4, 292-300.

TRUBIA, G., BUONO, S., PANERAI, S., ZINGALE, M., PASSANISIS, A., PIRRONE, C. and DI NUOVO, S. (2016) Siblings'perceptions in autism spectrum disorder compared with intellectual disability and typical development. Clinical Neuropsychiatry, 13, 2, 10-16. 
VERTÉ, S., ROEYERS, H. and BUYSSE, A. (2003) Behavioural problems, social competence and self-concept in siblings of children with autism. Child: Care, Health and Development, 29, 3, 193-205.

WALSH, F. (2003) Family resilience: A Framework for clinical practice. Family process, 42, 1, $1-18$.

WALTON, K.M. and INGERSOLL, B.R. (2015) Psychosocial adjustment and sibling relationships in siblings of children with autism spectrum disorders: Risk and protective factor. Journal of Autism and Developmental Disorders, 45, 2764-2778.

YODER, P., STONE, W.L., WALDEN, T. and MALESA, E. (2009) Predicting social impairment and ASD diagnosis in younger siblings of children with autism spectrum disorder. Journal of Autism and Developmental Disorders, 39, 10, 1381-1391.

\section{Correspondence}

Teresa Macedo Costa

Institute of Education

University of Minho

Portugal

Email: teresamacedo.ip@gmail.com 